\title{
Change of Transferrin Sialylation Differs between Mild Sepsis and Severe Sepsis and Septic Shock
}

\author{
Olga Gornik ${ }^{1}$, Ivan Gornik ${ }^{2}$, Ivana Zagorec Kolednjak ${ }^{1}$ and Gordan Lauc ${ }^{1,3}$
}

\begin{abstract}
Objective and Design To investigate the association between the severity of sepsis and changes in sialylation of serum proteins we have conducted a single center pilot study.

Subjects and Methods Sialylation of transferrin (with enzyme-linked lectin assay-ELLA) and total serum proteins (with colorimetric assay) as well as serum iron and transferrin levels were measured in 27 patients with sepsis through the first eight days of the disease.

Results Total serum sialylation increased in the first two days, transferrin sialylation decreased, while serum iron and transferrin fell. Patients who developed severe sepsis had either a small or marked change in transferrin sialylation while in patients with mild sepsis sialylation decreased moderately.

Conclusion We hypothesize that the change in transferrin sialylation could be a reflection of the intensity of inflammatory response which is insufficient if under-expressed and detrimental if over-expressed. This new feature is a potential marker of sepsis severity early in the disease.
\end{abstract}

Key words: sepsis, transferrin sialylation, protein sialylation, severity of sepsis, iron metabolism

(Intern Med 50: 861-869, 2011)

(DOI: 10.2169/internalmedicine.50.4704)

\section{Introduction}

Sepsis is a systemic response of an organism to a microbial pathogen $(1,2)$ which involves complex interactions between the infecting organism and host immune, inflammatory and coagulation mechanisms. Inflammatory response triggered by infection is modulated by anti-inflammatory mechanisms which strive to control potentially damaging effects of inflammation (3). Inability to control host responses in sepsis, more than the damaging effects of the pathogen itself, leads to organ dysfunction (severe sepsis) and circulatory failure (septic shock). These conditions have high mortality despite all modern treatment methods $(4,5)$. Early treatment remains the mainstay of management of sepsis and is especially stressed in the Surviving Sepsis Guidelines by creating the "Resuscitation bundle" of interventions that must be performed during the first 6 hours $(6,7)$.

Despite growing accumulation of knowledge about patho- physiological processes involved in sepsis, all aspects of this multifaceted phenomenon will not be elucidated soon $(8,9)$. Posttranslational modifications in protein structure have only begun to interest investigators of sepsis, with growing awareness of their importance in different processes $(10,11)$.

Glycosylation is the most diverse (post)translational protein modification. Majority of serum proteins are glycosylated and proper glycosylation is in many cases important for their half life and function. The most important feature of glycoproteins is their heterogeneity, since glycans can be present on the same molecule in numerous structural forms. Changes in glycan structures are reported in numerous diseases and serum glycoproteins reflect pathophysiological processes occurring in a cell at time of protein production. These alterations can be very specific and studies of serum protein glycosylation offer a good basis for diagnosis and prognosis of many diseases.

Sialic acid is the terminal monosccharide that may, or

\footnotetext{
${ }^{1}$ Department of Biochemistry and Molecular Biology, University of Zagreb, Faculty of Pharmacy and Biochemistry, Croatia, ${ }^{2}$ Division of Emergency and Intensive Care Medicine, Department of Medicine, Rebro University Hospital, Croatia and ${ }^{3}$ Genos Ltd, Glycobiology Division, Croatia

Received for publication October 18, 2010; Accepted for publication December 17, 2010

Correspondence to Dr. Olga Gornik, ogabela@pharma.hr
} 


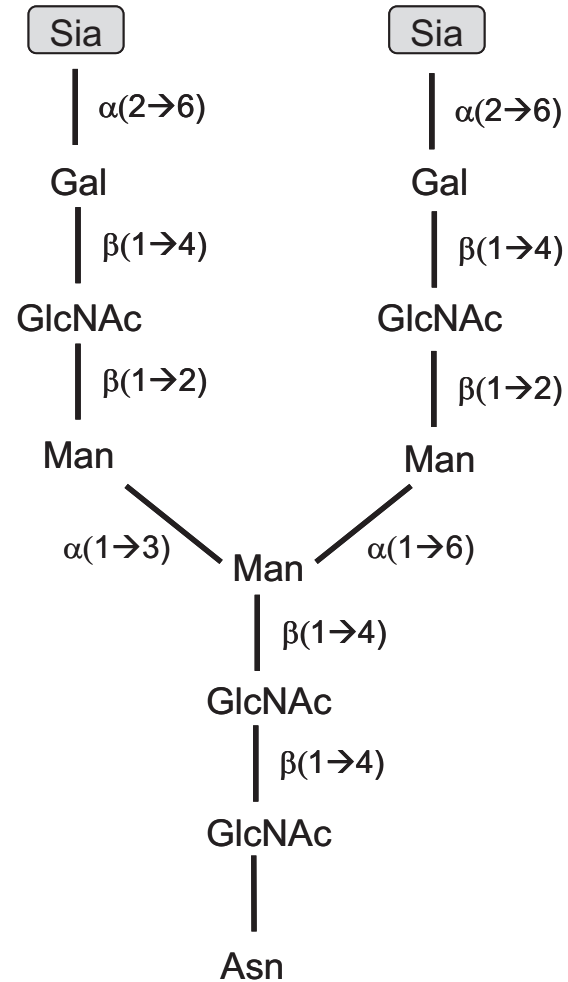

Figure 1. An example of glycan structure found on human serum glycoproteins. Simple biantennary structure ending with sialic acids is the predominant glycan present on serum glycoproteins. Two such glycans are also normally present on each transferrin molecule; one attached to Asn413, and other to Asn611.

may not, be present on each antenna of complex glycan molecules (Fig. 1). The changes in level of sialylation of certain glycoproteins have been observed in many pathological conditions. One such glycoprotein is transferrin, whose main physiological function is iron transport in blood (12). It is a negative acute phase protein, meaning that its concentration decreases during acute phase response. Biantennary or triantennary glycan structures which terminate in $\alpha 2,6$ linked sialic acids are attached to its polypeptide chain. Normally $85 \%$ of transferrin in human serum is tetrasialylated, containing two disialylated structures. Changes in transferrin glycosylation have been observed in malignant diseases (13), hereditary $(14,15)$ and acute conditions (16), and in inflammatory diseases as well (17). Disturbed sialylation is the most studied alteration of transferrin glycosylation, since it was found to be important for its proper function and also reflects disturbances in glycosylation machinery.

Despite widely accepted facts that glycosylation is very important in the process of inflammation and that the pathophysiology of sepsis is still not fully understood, information on glycosylation in sepsis is very scarce $(18,19)$. Decrease in transferrin sialylation has been reported in septic patients and in an animal model of septic shock (20), but its change has never been followed through disease in humans.

We have investigated the changes in sialylation of human transferrin in patients with sepsis during the first 8 days of the disease and studied their association with severity of disease.

\section{Patients and Methods}

\section{Definitions}

Systemic inflammatory response syndrome (SIRS), sepsis (SIRS with presumed infectious origin), organ failure, severe sepsis (sepsis and organ failure) and septic shock (sepsis with refractory hypotension) were defined according to the usual criteria $(1,2)$.

\section{Patients}

Patients with sepsis were approached for participation after establishing the diagnosis in the Emergency Department of University Hospital. Included were adult ( $\geq 18$ years) patients that fulfilled the criteria for sepsis and were admitted to the hospital within the first 12 hours of feeling ill and had no organ failure (severe sepsis) at presentation or during the first 24 hours after admission. Patients with severe disease at admission were excluded because we wanted to evaluate changes of sialylation as predictors of development of severe disease later.

Exclusion criteria were: known anemia, iron deficit or disturbance of iron metabolism; heavily disturbed general health due to other acute or chronic disease; imminent mortal outcome; sepsis as a secondary diagnosis; treatment with pharmaceuticals that inhibit neuraminidases; or any condition that could significantly influence the course and outcome of disease. All patients signed informed consent to participate in the study.

\section{Blood sampling}

The blood samples were taken from patients with sepsis on four occasions: at the moment of inclusion (Day 1), on the first day following admission (after $24 \pm 2$ hours; Day 2) and on the fifth and the eighth day of hospitalization.

\section{Disease course and outcome}

Progression of sepsis to severe sepsis or septic shock during the hospitalization was evaluated for all patients at discharge. Patients who developed severe sepsis and septic shock were evaluated as a single group for comparisons with the group with mild sepsis.

We calculated APACHE (Acute Physiology And Chronic Health Evaluation) II score and SOFA (Sequential Organ Function Assessment) score at inclusion, on the days of blood sampling (days 2, 5 and 8) and later in cases of disease progression. The highest scores during the hospitalization were used as measures of disease severity. Total hospital length of stay (LOS) was also noted as a measure of severity and hospital mortality was used as the outcome measure.

Patients were admitted to medical wards; participation in 
this study had no influence on treatment strategy or transfer to the ICU (intensive care unit); physicians involved in this study were not involved in the treatment of these patients. Persons involved in the analysis of transferrin sialylation were blinded to any of the patients' clinical characteristics.

\section{Measurements of C-reactive protein}

C-reactive protein was measured by quantitative immunoturbidimetric latex test on Olympus AU400 at the times of blood taking and later at the discretion of attending physicians. Highest CRP was noted as a measure of disease severity.

\section{Iron, transferrin and ferritin measurements}

Serum iron was determined by precision photometry (21). Transferrin concentrations were determined by immunoturbidimetric method (22). Serum ferritin was measured by electrochemiluminescence immunoassay (ECLIA; Roche e601).

\section{Transferrin sialylation assay}

The transferrin sialylation was analyzed by enzyme-linked lectin assay (ELLA) (19) that measures $\alpha 2,6$ linked sialic acid using Sambucus nigra (SNA) lectin. We briefly describe the method.

Microtiter plates (Immunoplates Polysorb, Nunc, Wiesbaden, Germany) were coated with $50 \mu \mathrm{L}$ of polyclonal antibodies against human transferrin (Sigma cat. \#T6265) diluted 1:1000 in $100 \mathrm{mmol} / \mathrm{L} \mathrm{Na-carbonate} \mathrm{buffer} \mathrm{pH} 9.6$ at $4^{\circ} \mathrm{C}$ and incubated for $16 \mathrm{~h}$. Unbound antibodies were removed by washing with $200 \mu \mathrm{L}$ of $50 \mathrm{mmol} \mathrm{dm}^{-3} \mathrm{Tris} / \mathrm{HCl}$, $150 \mathrm{mmol} / \mathrm{L} \mathrm{NaCl}, 0.1 \%$ (v/v) Tween 20, pH 7.5 (TBST) three times for ten minutes. In order to prevent binding of lectins to carbohydrate determinants on antibodies, antibodies were treated with $75 \mu \mathrm{L}$ of $20 \mathrm{mmol} / \mathrm{L} \mathrm{HIO}_{4}$ at $4{ }^{\circ} \mathrm{C}$ for $30 \mathrm{~min}$. Microtiter wells were then blocked with $200 \mu \mathrm{L}$ of $3 \%$ BSA in TBS pH 7.5 for 60 minutes at $37^{\circ} \mathrm{C}$. For each assay, $100 \mu \mathrm{L}$ of serum diluted $1: 50$ in TBST was added and incubated for 1 hour at $37^{\circ} \mathrm{C}$. The plate was washed as before.

Sialic acids on captured transferrin were detected by addition of $100 \mu \mathrm{L}$ of $2 \mu \mathrm{g} / \mathrm{mL}$ biotinylated SNA lectin (Vector Laboratories, Burlingame, CA, USA) in $50 \mathrm{mmol} / \mathrm{L}$ Tris/ $\mathrm{HCl}, 150 \mathrm{mmol} / \mathrm{L} \mathrm{NaCl}, \mathrm{pH} 7.5$ (TBS). After $90 \mathrm{~min}$ incubation at $37^{\circ} \mathrm{C}$, the plate was washed as before and incubated with $100 \mu \mathrm{L}$ of extravidin conjugated with alkaline phosphatase (extravidine-AP, Sigma) diluted 1:30000 in TBS and incubated at $37^{\circ} \mathrm{C}$ for $1 \mathrm{~h}$. After washing the plate three times, the color was developed with $100 \mu \mathrm{L}$ of 50 mmol dm ${ }^{-3}$ p-nitrophenylphosphate substrate (Sigma) in 50 $\mathrm{mmol} / \mathrm{L} \mathrm{Na}_{2} \mathrm{CO}_{3}, 1 \mathrm{mmol} / \mathrm{L} \mathrm{MgCl}_{2}$ for $30 \mathrm{~min}$. The signal was read on a microplate reader using a standard photometric method at $405 \mathrm{~nm}$. All samples were analyzed in triplicate.

To create a comparison curve different amounts of transferrin $(0-200 \mathrm{ng})$, diluted in $100 \mu \mathrm{L}$ of TBS, were adsorbed directly to microtiter plates (for 3 hours). Results are expressed in "transferrin units" (TU) defined as the amount of transferrin resulting in corresponding level of SNA binding.

\section{Protein concentration}

Protein concentration was measured in microtiter plate using commercial Sigma bicinchoninic acid (BCA) assay; dilutions of $200-1,000 \mu \mathrm{g} / \mathrm{mL}$ of bovine serum albumin were used to create a standard curve.

\section{Sialylation of total serum proteins}

Sialic acid present on serum proteins was analyzed by modified Svennerholm method (23-25) adapted for application in microtiter plates.

$800 \mu \mathrm{L}$ of chloroform, $1,600 \mu \mathrm{L}$ of methanol and $200 \mu \mathrm{L}$ of water were added to $100 \mu \mathrm{L}$ of serum in glass tube to precipitate the proteins. The sample was centrifuged for 20 minutes at 3,000 g. Supernatant was decanted and precipitate was used for further analysis. $500 \mu \mathrm{L}$ of $0.1 \mathrm{M} \mathrm{H}_{2} \mathrm{SO}_{4}$ was added to each tube, the precipitate was resuspended, left for 1 hour at $80^{\circ} \mathrm{C}$ and then centrifuged for 10 minutes at $3000 \mathrm{~g}$. For each reaction, $25 \mu \mathrm{L}$ of supernatant was put on a microtiter plate. $25 \mu \mathrm{L}$ of $0.1 \mathrm{M} \mathrm{CaCl}_{2}$ and $10 \mu \mathrm{L}$ of 0.04 $\mathrm{M} \mathrm{NaIO}_{4}$ were added to each well. The plate was mixed and incubated for 20 minutes on ice. $65 \mu \mathrm{L}$ of resorcinol reagent $\left(0.6 \%\right.$ resorcinol, $\left.26 \% \mathrm{HCl}, 0.004 \% \mathrm{CuSO}_{4}\right)$ was added and the plate was incubated for 5 minutes on ice, and then for 30 minutes at $80^{\circ} \mathrm{C}$.

The plate was left to cool and then centrifuged 3 minutes at $1,000 \times \mathrm{g}$. The reaction was stopped by the addition of tertiarybutanol $(62.5 \mu \mathrm{L})$ and the absorbance was read at 630 $\mathrm{nm}$. All samples were analyzed in triplicates. The method modified in this way has increased specificity for sialic acid and allows rapid and cheap screening of total protein sialylation.

Protein sialylation is expressed as concentration of sialic acid divided by protein concentration.

\section{Statistical analyses}

MecCalc $^{\mathrm{TM}}$ v. 7.2.1.0 and SPSS v 14.0 statistical software was used for statistical analyses. Due to the small sample size, non-parametric tests were used regardless of the distribution type for any measured parameter. Accordingly, continuous variables are presented as median with range, categorical as absolute and relative frequencies. Wilcoxon's test (paired and unpaired, as appropriate) was used for group comparisons of continuous variables; chi-square test for categorical variables. Smirnov Kolmogorov test was used to compare distributions and variance ratio test ( $\mathrm{F}$ test) was used to compare differently distributed data. Spearman's rank correlation was used for correlation analyses.

Statistical significance was set at $\alpha=0.05$.

This study was performed in conformance to the ethical guidelines of the 1975 Declaration of Helsinki and approved by the ethics committees of the Clinical Hospital Centre Zagreb and the University of Zagreb, Faculty of Pharmacy and 
Table 1. Basic Characteristics of Patients

\begin{tabular}{lllll}
\hline Parameter & All patients & $\begin{array}{l}\text { Mild } \\
\text { sepsis }\end{array}$ & $\begin{array}{l}\text { Severe sepsis \& } \\
\text { septic shock }\end{array}$ & $\begin{array}{l}\text { Mild vs. severe sepsis \& } \\
\text { septic shock }\end{array}$ \\
\hline n (\%) & 27 & 15 & 12 & \\
Age (years) & $76(40-93)$ & $70(40-91)$ & $77(59-93)$ & $\mathrm{p}=0.118$ \\
Sex (female) & $13(48.2 \%)$ & $8(53.3 \%)$ & $5(41.6 \%)$ & $\mathrm{p}=0.829$ \\
Etiology & & & & \\
- gram + & $10(37.0 \%)$ & $5(33.3 \%)$ & $5(41.7 \%)$ & \\
- gram - & $11(40.7 \%)$ & $7(46.7 \%)$ & $4(33.3 \%)$ & 0.921 \\
- mixed gram+ / gram- & $2(7.4 \%)$ & $1(6.7 \%)$ & $1(8.3 \%)$ & \\
- negative cultures & $4(14.8 \%)$ & $2(13.3 \%)$ & $2(16.7 \%)$ & \\
$\begin{array}{l}\text { Admission APACHE II } \\
\text { Highest SOFA score }\end{array}$ & $13(8-17)$ & $12(8-17)$ & $13(8-14)$ & $\mathrm{p}=0.083$ \\
& $6(2-17)$ & $4(2-8)$ & $9(6-17)$ & $\mathbf{p}<\mathbf{0 . 0 0 1}$ \\
Survivors LOS (days) & & & & $\mathbf{p}=\mathbf{0 , 0 3 9}$ \\
Hospital mortality & $10(27.0 \%)$ & $3(20.0 \%)$ & $7(58.3 \%)$ & $\mathrm{p}=0.099$ \\
\hline
\end{tabular}

Table 2. Serum Iron, Transferrin and Ferritin Concentrations through the First 8 Days of Hospitalisation. Values are Medians with Ranges

\begin{tabular}{llll}
\hline & All patients & Mild sepsis & $\begin{array}{l}\text { Severe sepsis } \\
\text { \& septic shock }\end{array}$ \\
\hline $\begin{array}{l}\text { Iron }(\boldsymbol{\mu m o l} / \mathbf{L})^{*} \\
\text { - Day 1 }\end{array}$ & $10.2(6.9-16.0)$ & $9.5(6.9-16.0)$ & $10.4(7.8-16)$ \\
- Day 2 & $3.2(1.9-6.8)$ & $3.5(1.9-6.8)$ & $2.9(2.0-4.2)$ \\
- Day 5 & $3.1(1.2-7.2)$ & $3.3(1.2-7.2)$ & $2.4(1.5-5.2)$ \\
- Day 8 & $3.3(1.9-5.8)$ & $3.8(1.9-5.8)$ & $3.1(2.2-4.1)$ \\
Transferrin $(\mathbf{g} / \mathbf{L})^{*}$ & & & \\
- Day 1 & $1,7(1.2-2.2)$ & $1.7(1.2-2.2)$ & $1.7(1.2-2.1)$ \\
- Day 2 & $1.1(0.4-1.5)$ & $0.9(0.4-1-5)$ & $1.1(0.6-1.4)$ \\
- Day 5 & $1.3(0.6-2.0)$ & $1.2(0.6-2.0)$ & $1.3(0.6-1.8)$ \\
- Day 8 & $1.2(1.2-1.9)$ & $1.1(0.4-1.8)$ & $1.3(0.3-1.9)$ \\
Ferritin $(\boldsymbol{\mu g} / \mathbf{L})^{*}$ & & & \\
- Day 1 & $324(246-435)$ & $346(246-398)$ & $324(265-435)$ \\
- Day 2 & $822(571-1259)$ & $764(571-1096)$ & $853(588-1259)$ \\
- Day 5 & $769(429-1128)$ & $727(429-1128)$ & $866(570-1045)$ \\
- Day 8 & $922(476-1246)$ & $922(476-1180)$ & $923(686-1246)$ \\
\hline
\end{tabular}

*Normal ranges: iron: 8-30 $\mu \mathrm{mol} / \mathrm{L}$; transferrin 2.0-3.6 g/L; ferritin: 15-400 $\mu \mathrm{g} / \mathrm{L}$

Biochemistry.

\section{Results}

During the study period, 32 patients that fulfilled the inclusion criteria were asked to participate in the study; 27 patients agreed and were included. Twelve of these patients $(44.4 \%)$ were male; median age of the group was 60 (4093) years. Severe sepsis or septic shock developed in 12 patients after the first day of admission. Median time from admission to the occurrence of severe sepsis or shock was 3 days (range 2-7 days). Basic characteristics of patients are summarized in Table 1.

No patient characteristics available at admission or during first two days (i.e. age, APACHE II score, biomarkers such as CRP, white blood count etc.) could predict the course of sepsis, i.e. predict which patient would develop severe disease.

\section{Serum iron, transferrin and ferritin levels}

Concentrations of serum iron, transferrin and ferritin are shown in Table 2. Iron concentrations were already at lower end or below normal on admission and fell significantly $(\mathrm{p}<$ 0.001) on the second day; they remained low through the next two measurements. Transferrin levels were already low at admission, with a significant drop the next day $(\mathrm{p}=0.001)$ and no significant change in the subsequent 5 days. Ferritin concentrations were close to the normal upper limit at admission, but rose significantly on Day $2(\mathrm{p}<0.001)$. There was no significant difference in iron, transferrin or ferritin concentrations on any day between patients with mild sepsis and those with severe sepsis.

\section{Sialylation of transferrin during hospitalization and its relation to disease severity}

Median transferrin sialylation of all patients at admission 


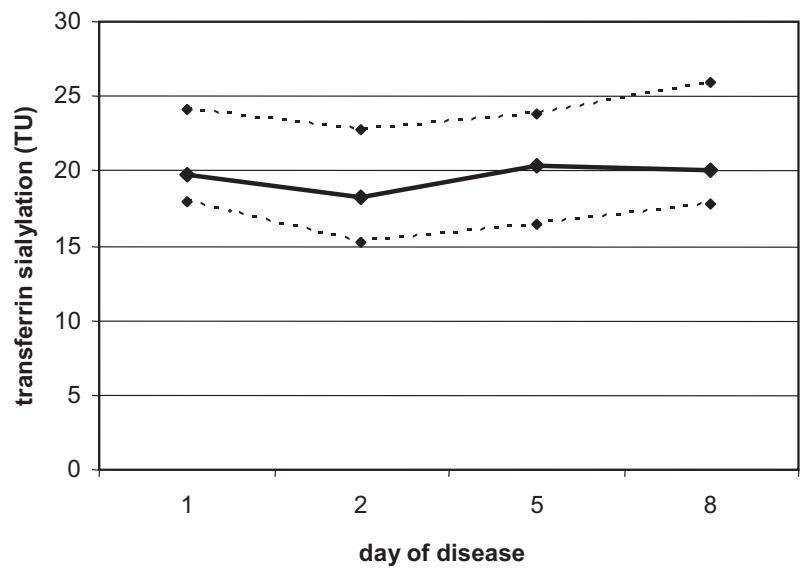

Figure 2. Sialylation of transferrin during the first eight days of hospitalization of septic patients determined by enzyme-linked lectin assay. The tick full line connects medians; dotted lines connect 25 th and 75 th percentiles.

was 19.7 TU (9.7-31.1); there was no difference in transferrin sialylation between patients who would have mild sepsis $(\mathrm{M}=23.3 \mathrm{TU})$ and patients who would develop severe sepsis or septic shock $(\mathrm{M}=19.6 \mathrm{TU} ; \mathrm{p}=0.364)$. This sialylation level also did not differ from the levels in healthy controls that we determined in our previous work using the same method (26).

Transferrin sialylation during the first eight days of hospitalization of septic patients changed as shown in Fig. 2.

The most prominent change observed was a rapid decrease in transferrin sialylation between Day 1 [19.7 TU (9.7-31.1)] and Day 2 [18.3 TU (5.1-28.1); $\mathrm{p}<0.001]$.

During the next three days transferrin sialylation increased to a level slightly above that at admission (Day $520.3 \mathrm{TU}$ (6.5-31.3), so it was significantly higher than on Day 2; $\mathrm{p}=$ 0.046). On the eighth day, sialylation did not further differ from that on the fifth day (20.2 TU (8.7-30.1); $\mathrm{p}=0.899)$.

The relative change in transferrin sialylation did not correlate with serum iron, ferritin or transferrin concentrations, or with relative changes of these variables.

\section{Relationship of transferrin sialylation and disease severity}

When transferrin sialylation was examined for each patient with sepsis it was observed that patients who developed severe sepsis or septic shock had either a very prominent decrease in transferrin sialylation between Day 1 and Day 2 or had almost no change in transferrin sialylation [decrease $29 \%(8.3 \%-74.1 \%)$; or increase $0.8 \%$ (increase $2 \%$ decrease $2.9 \%$ )] compared to patients with mild disease whose sialylation decreased by median $9.5 \%(2.6 \%-18 \%)$. This change in transferrin sialylation is shown in Fig. 3, while Fig. 4 shows the individual data of transferrin sialylation on the first and second day of disease for patients with mild sepsis and severe forms of sepsis. Since one group of results (severe group) was bimodal, we used the Variance ratio test to compare variances of the groups; it showed that

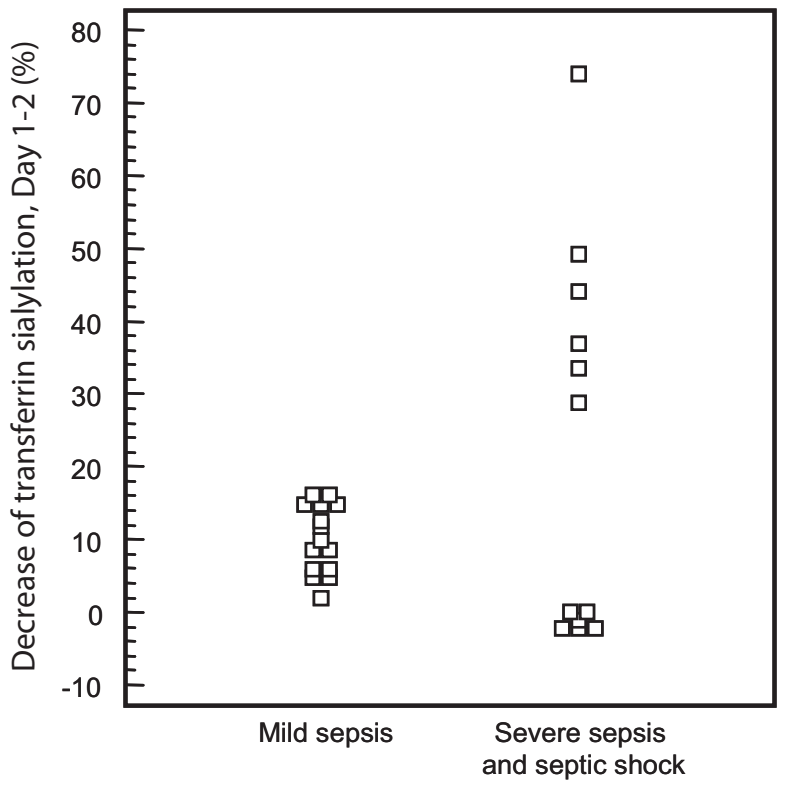

Figure 3. Relative decrease $(\%)$ in transferrin sialylation between first and second day of hospitalization in patients who developed mild sepsis in comparison to patients who developed severe sepsis or septic shock. Presented is statistical significance of Variance ratio test.

the two groups differ significantly in their variance $(\mathrm{p}<$ $0.001)$.

The different change in sialylation in the "severe" group was not related to any other patient characteristic tested; we could not identify any characteristic (i.e. mortality, disease severity, Gram positive or Gram negative cultures) that was associated with a small or large change in sialylation.

\section{Sialylation of total serum proteins in sepsis}

Sialylation of total serum proteins was expressed as concentration of sialic acid measured on serum proteins divided by protein concentration for each sample. At the time of admission total protein sialylation was $0.95 \times 10^{-2}\left(0.48 \times 10^{-2}\right.$ $\left.1.7 \times 10^{-2}\right)$. There was no statistically significant difference between patients with mild sepsis $0.86 \times 10^{-2}\left(0.48 \times 10^{-2}-1.7 \times\right.$ $\left.10^{-2}\right)$, severe sepsis $0.97 \times 10^{-2}\left(0.83 \times 10^{-2}-1.4 \times 10^{-2}\right)$ or septic shock $0.96 \times 10^{-2}\left(0.86 \times 10^{-2}-1.01 \times 10^{-2}\right), \mathrm{p}=0.781$, although sialylation was higher in patients with severe conditions.

The level of protein sialylation changed during the hospitalization as shown in Fig. 5.

The increase in protein sialylation was observed during the first eight days of hospitalization. Sialylation on day 1 $\left(\mathrm{M}=0.92 \times 10^{-2}\right)$ was lower than on day $2\left(\mathrm{M}=1.05 \times 10^{-2}\right), \mathrm{p}=$ 0.037 . Further change in sialylation on day $5\left(\mathrm{M}=1.06 \times 10^{-2}\right)$ did not significantly differ than on day $2, \mathrm{p}=0.430$, as well as on day $8\left(\mathrm{M}=1.15 \times 10^{-2}\right)$ compared to day $5, \mathrm{p}=0.76$. There was no difference in relative changes of protein sialylation between mild sepsis and severe sepsis/septic shock. 

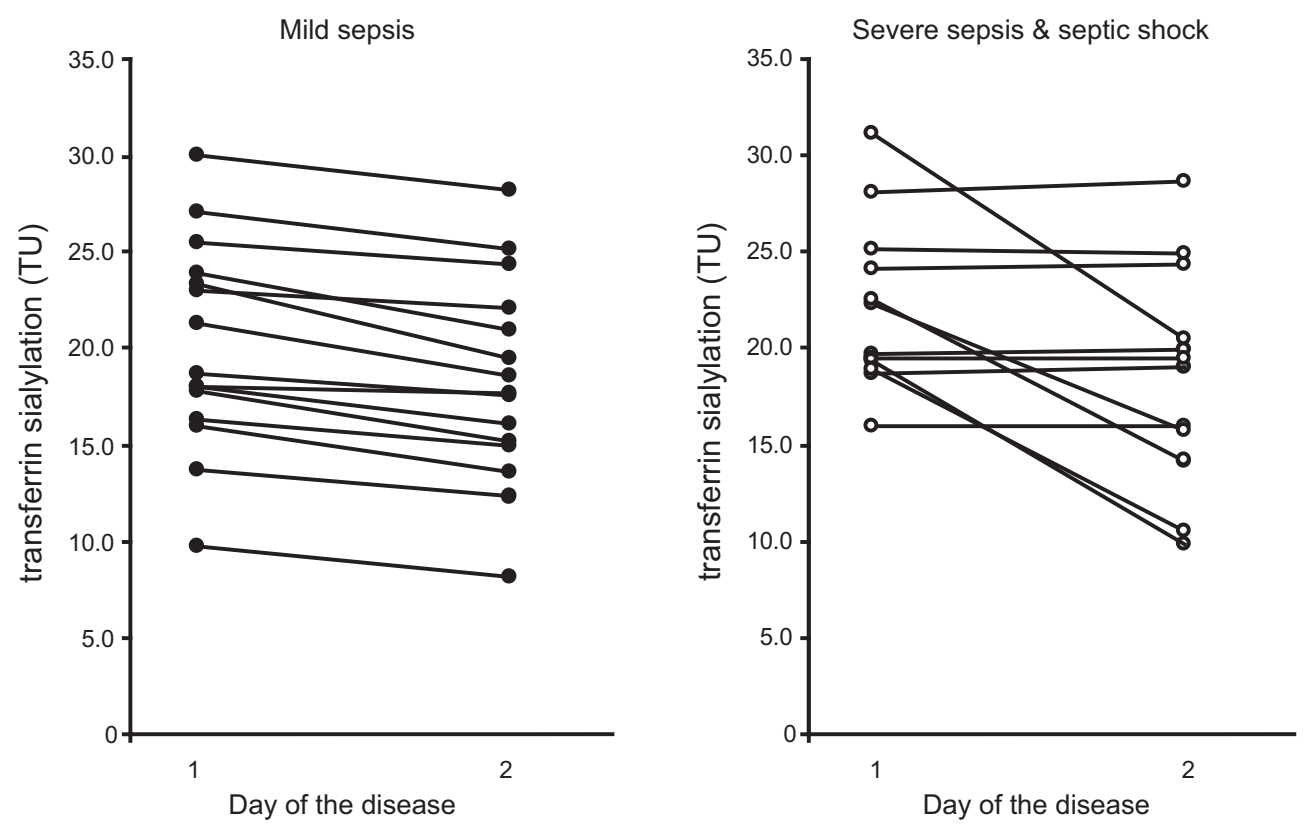

Figure 4. Individual data of transferrin sialylation at admission and on the second day of the disease, divided according to severity of sepsis.

\section{Relation between measured parameters and $C$ - reactive protein}

Correlation between transferrin sialylation and C-reactive protein values in septic patients was very low and with no statistical significance $\mathrm{r}=0.087 ; \mathrm{p}=0.408$, while total protein sialylation and C-reactive protein showed a positive correlation $\mathrm{r}=0.345 ; \mathrm{p}=0.001$.

\section{Discussion}

The present results show that during the first several days of sepsis there are marked changes in transferrin sialylation, and total serum protein sialylation. We also observed significant changes in serum iron, transferrin and ferritin concentrations in the first two days of disease.

Low iron and transferrin were present already at presentation in the emergency department which illustrates the rapidity of iron depletion in systemic inflammation. Ferritin levels were also above average at admission, and tripled from Day 1 to Day 2, demonstrating storage of iron depleted from serum. These results correspond to those previously published on iron metabolism in ICU patients (27-29).

Our results of temporal changes in transferrin sialylation in sepsis are the first reported in humans. Changes of transferrin sialylation was described in 2005 by Piagnerelli and colleagues (20) who found increased levels of undersialylated transferrin, increased free sialic acid and lower transferrin levels in septic patients compared to healthy controls and postoperative non-septic patients. They also described temporal changes of transferrin sialylation in a sheep model of septic shock which correspond with our findings. However, they did not investigate transferrin sialylation changes over time in humans or stratify patients with sepsis according to severity of disease. No data have been published onglycosylation changes in other kinds of shock.

Given that the principal role of transferrin is iron transport, it is reasonable to suppose a relationship between transferrin desialylation and iron metabolism. Transferrin concentrations decrease rapidly in inflammation, apparently to deprive bacteria of iron needed for growth $(30,31)$. Sialylation of transferrin influences its half-life and its function: desialylated transferrin is responsible for faster delivery of iron to hepatic storage (32) and also has a shorter half-life than normally sialylated transferrin (30); transferrin with a low sialic acid content also increases iron turnover and leads to iron loading of the hepatocyte (33).

It seems that the reduction of serum transferrin and iron levels is not absolutely dependent on transferrin desialylation, although their decrease is simultaneous with transferrin desialylation. Transferrin and iron were comparably low in patients with high, moderate and low desialylation. Other mechanisms are obviously involved in transferrin and iron depletion, illustrating the importance of this phenomenon in the inflammatory response to infection.

Mechanisms of transferrin desialylation are not fully understood. Since the half-life of the molecule is fairly long (34), the observed rapid changes of glycosylation can be explained either by increased activity of neuraminidases, higher clearance of tetrasialylated transferrin from plasma or bacterial activity. More than one mechanism or even all of them could be involved. Increased neuraminidase activity was previously suggested as the most probable mechanism (20). It was recently shown that neuraminidase activity increases in sepsis which leads to erythrocyte desialylation (35) and that neuraminidase 1 , one of the four human neuraminidases, has an important role in the immune response and inflammation (36-39). However, the present re- 


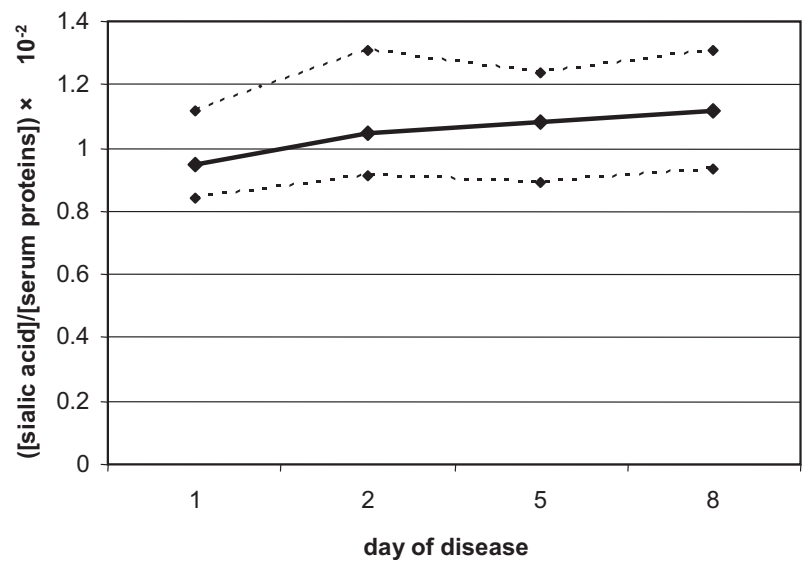

Figure 5. Total protein sialylation given as sialic acid measured on serum proteins $(\mathrm{mg} / 100 \mathrm{~mL})$ divided by protein concentration $(\mathrm{mg} / \mathrm{mL})$ during first eight days of hospitalization of septic patients. The tick full line connects medians; dotted lines connect 25 th and 75 th percentiles.

sults show that, in contrast to transferrin, total plasma proteins do not show a decrease in their sialylation levels. The existence of the specific neuraminidase (either from pathogen or domestic), or different affinites for certain proteins, could explain this event. The acute phase proteins are highly sialylated and their high production can actually compensate the results of neuraminidase activity, so this effect that occurs early in the inflammatory response, could be expressed to a higher extent on transferrin molecules whose concentration decreases early in the inflammation. The previously mentioned role of transferrin as an iron transporter and the bacterial need for iron could also play an important role in the difference of sialylation behavior, especially since transferrin sialylation was suggested to play a role in iron binding affinity.

The return of transferrin sialylation to baseline levels on Day 5 could suggest clearance of desialylated transferrin by hepatic receptors, since it coincides with the fall of serum transferrin and the rise in ferritin.

Comparison of changes in transferrin sialylation in patients with mild sepsis and in patients who developed organ failure (severe sepsis) or septic shock, revealed an interesting phenomenon. It seems that patients with "moderate" desialylation in the first two days of disease have a better disease course and outcome than those with low and high extremes of desialylation. We can only speculate on possible explanations for this phenomenon. Since protein glycosylation in humans is very stabile on a day-to-day basis, if there are no physiological (i.e. pregnancy) or pathological (i.e. inflammation, tumors) conditions (40), any change in protein glycosylation, including transferrin must be a response to a stress, in this case infection and inflammation. The mediators instigating transferrin desialylation are not known, but it is feasible that they include the typical pro-inflammatory mediators, such as interleukin 1 (IL-1) and tumor necrosis factor alpha (TNF- $\alpha)$ that mediate other changes of iron me- tabolism (41), such as the induction of ferritin synthesis, induction of lactoferrin and hepcidin (42-44). It can be assumed that the intensity of inflammatory response correlates with the desialylation of transferrin, or reversely, that desialylation of transferrin reflects the intensity of inflammation. Patients with a "moderate" change in transferrin sialylation would therefore have a "reasonable" or "adequate" systemic inflammatory response which is beneficial for fighting the infection and not harmful for the host. "Reduced" desialylation of transferrin would reflect a poor inflammatory response and incapability to fight the infection leading to severe disease, while too strong of an inflammatory response that leads to organ failure and/or shock would be reflected by a high reduction of transferrin sialylation.

The results of the present study that investigated transferrin sialylation in acute pancreatitis (18) support these speculations. We found that more expressed desialylation of transferrin during the first two days of disease is associated with the development of severe pancreatitis, while patients with a smaller change in transferrin sialylation had mild disease. Activation of systemic inflammatory response is one of the main reasons for the development of severe pancreatitis, in which there is usually no infectious pathogen to encounter in the first days. Systemic inflammation is in this context mostly detrimental and there is no "reasonable" or "adequate" inflammatory response, as in sepsis.

Among the patients with severe sepsis and septic shock, we could not identify any characteristic that could be associated with a low or high desialylation profile. Detailed analysis of inflammatory mechanisms might produce some answers which will be a subject of further studies.

Even though we can not provide definite physiological explanation for our observations, their potential practical value as a predictor of severity in septic patients is more easily understandable. Early identification of patients with a higher risk of organ failure or circulatory collapse in sepsis could lead to earlier admission to intensive care units and more aggressive treatment. Since it is known that earlier treatment of severe sepsis is one of the most important factors in improving survival, identification of such patients could be of immense value. Among the patients in our study who were all admitted with "mild" sepsis, some developed severe forms of disease, and they could not have been identified in advance. Since the median time when severe disease was identified was 3 days, identification of patients with a high risk of developing severe sepsis and septic shock on first post-admission day using the newly discovered marker would clearly be an improvement and would surely lead to saving of lives. Further studies are of course needed to investigate the value of this potential predictor of severity of sepsis and to explain its association with inflammatory response.

In conclusion we can repeat that acute inflammatory response in early sepsis is associated with marked changes in transferrin sialylation which differ in patients who develop severe forms of sepsis from patients with mild sepsis. This 
difference makes desialylation of transferrin a potential predictive marker of the severity of sepsis.

The authors state that they have no Conflict of Interest (COI).

\section{Acknowledgement}

This work was supported by grant \#309-0061194-2023 from the Croatian Ministry for Science, Education and Sport and by FP6 EuroPharm grant from the EC.

\section{References}

1. Levy MM, Fink MP, Marshall JC, et al. 2001 SCCM/ESICM/ ACCP/ATS/SIS International Sepsis Definitions Conference. Intensive Care Med 29: 530-538, 2003.

2. American College of Chest Physicians/Society of Critical Care Medicine Consensus Conference. Definitions for sepsis and organ failure and guidelines for the use of innovative therapies in sepsis. Crit Care Med 20: 864-874, 1992.

3. Cinel I, Dellinger RP. Advances in pathogenesis and management of sepsis. Curr Opin Infect Dis 20: 345-352, 2007.

4. Esper AM, Martin GS. Extending international sepsis epidemiology: the impact of organ dysfunction. Crit Care 13: 120, 2009.

5. Harrison DA, Welch CA, Eddleston JM. The epidemiology of severe sepsis in England, Wales and Northern Ireland, 1996 to 2004: secondary analysis of a high quality clinical database, the ICNARC Case Mix Programme Database. Crit Care 10: R42, 2006.

6. Dellinger RP, Carlet JM, Masur H, et al. Surviving sepsis campaign guidelines for management of severe sepsis and septic shock. Intensive Care Med 30: 536-555, 2004.

7. Dellinger RP, Levy MM, Carlet JM, et al. Surviving sepsis campaign: international guidelines for management of severe sepsis and septic shock: 2008. Intensive Care Med 34: 17-60, 2008.

8. Marshall JC. The pathogenesis and molecular biology of sepsis. Crit Care Resusc 8: 227-229, 2006.

9. Cinel I, Opal SM. Molecular biology of inflammation and sepsis: a primer. Crit Care Med 37: 291-304, 2009.

10. Remick DG. Applied molecular biology of sepsis. J Crit Care 10: 198-212, 1995.

11. Hayashi S, Gillam IC, Bondy G, Duronio V, Hogg JC. Molecular mechanisms of sepsis: molecular biology of the cell. J Crit Care 10: 82-95, 1995.

12. de Jong G, van Dijk JP, van Eijk HG. The biology of transferrin. Clin Chim Acta 190: 1-46, 1990.

13. Yamashita K, Koide N, Endo T, Iwaki Y, Kobata A. Altered glycosylation of serum transferrin of patients with hepatocellular carcinoma. J Biol Chem 264: 2415-2423, 1989.

14. Sturiale L, Barone R, Fiumara A, et al. Hypoglycosylation with increased fucosylation and branching of serum transferrin $\mathrm{N}$ glycans in untreated galactosemia. Glycobiology 15: 1268-1276, 2005.

15. Edwards M, McKenzie F, O'Callaghan S, et al. Prenatal diagnosis of congenital disorder of glycosylation type Ia (CDG-Ia) by cordocentesis and transferrin isoelectric focussing of serum of a 27week fetus with non-immune hydrops. Prenat Diagn 26: 985-988, 2006.

16. Arndt T, Hackler R, Muller T, Kleine TO, Gressner AM. Increased serum concentration of carbohydrate-deficient transferrin in patients with combined pancreas and kidney transplantation. Clin Chem 43: 344-351, 1997.

17. Grzymislawski M, Derc K, Sobieska M, Wiktorowicz K. Microheterogeneity of acute phase proteins in patients with ulcerative colitis. World J Gastroenterol 12: 5191-5195, 2006.

18. Gornik O, Lauc G. Glycosylation of serum proteins in inflammatory diseases. Dis Markers 25: 267-278, 2008.
19. Gornik O, Lauc G. Enzyme linked lectin assay (ELLA) for direct analysis of transferrin sialylation in serum samples. Clin Biochem 40: 718-723, 2007.

20. Piagnerelli M, Boudjeltia KZ, Nuyens V, et al. Rapid alterations in transferrin sialylation during sepsis. Shock 24: 48-52, 2005.

21. van Haga PR. Microdetermination of serum iron and of ironbinding capacity by precision photometry. Mikrochim Acta 542547, 1976.

22. Cynober L, Le Boucher J, Giboudeau J. Immunoturbidimetric determination of serum transferrin on a Kone Progress autoanalyser. J Automat Chem 11: 40-41, 1989.

23. Svennerholm L. On the isolation and characterization of N-acetylsialic acid. Acta Soc Med Ups 61: 74-85, 1956.

24. Svennerholm L. Quantitative estimation of sialic acids. II. A colorimetric resorcinol-hydrochloric acid method. Biochim Biophys Acta 24: 604-611, 1957.

25. Martensson E, Raal A, Svennerholm L. Sialic acids in blood serum. Biochim Biophys Acta 30: 124-129, 1958.

26. Gornik O, Gornik I, Gasparovic V, Lauc G. Change in transferrin sialylation is a potential prognostic marker for severity of acute pancreatitis. Clin Biochem 41: 504-510, 2008.

27. von Ahsen N, Muller C, Serke S, Frei U, Eckardt KU. Important role of nondiagnostic blood loss and blunted erythropoietic response in the anemia of medical intensive care patients. Crit Care Med 27: 2630-2639, 1999.

28. Bobbio-Pallavicini F, Verde G, Spriano P, et al. Body iron status in critically ill patients: significance of serum ferritin. Intensive Care Med 15: 171-178, 1989.

29. Rodriguez RM, Corwin HL, Gettinger A, Corwin MJ, Gubler D, Pearl RG. Nutritional deficiencies and blunted erythropoietin response as causes of the anemia of critical illness. J Crit Care 16: 36-41, 2001.

30. Wizorek JJ, Turnbull IR, Buchman TG. Iron overload before cecal ligation and puncture increases mortality. Shock 20: 52-55, 2003.

31. Piagnerelli M, Vincent JL. Role of iron in anaemic critically ill patients: it's time to investigate! Crit Care 8: 306-307, 2004.

32. Rudolph JR, Regoeczi E, Chindemi PA, Debanne MT. Preferential hepatic uptake of iron from rat asialotransferrin: possible engagement of two receptors. Am J Physiol 251: G398-G404, 1986.

33. Beguin Y, Bergamaschi G, Huebers HA, Finch CA. The behavior of asialotransferrin-iron in the rat. Am J Hematol 29: 204-210, 1988.

34. Stibler H. Carbohydrate-deficient transferrin in serum: a new marker of potentially harmful alcohol consumption reviewed. Clin Chem 37: 2029-2037, 1991.

35. Piagnerelli M, Boudjeltia KZ, Rapotec A, et al. Neuraminidase alters red blood cells in sepsis. Crit Care Med 37: 1244-1250, 2009.

36. Stamatos NM, Liang F, Nan X, et al. Differential expression of endogenous sialidases of human monocytes during cellular differentiation into macrophages. FEBS J 272: 2545-2556, 2005.

37. Liang F, Seyrantepe V, Landry K, et al. Monocyte differentiation up-regulates the expression of the lysosomal sialidase, Neu1, and triggers its targeting to the plasma membrane via major histocompatibility complex class II-positive compartments. J Biol Chem 281: 27526-27538, 2006.

38. Nan X, Carubelli I, Stamatos NM. Sialidase expression in activated human T lymphocytes influences production of IFN-gamma. J Leukoc Biol 81: 284-296, 2007.

39. Seyrantepe V, Iannello A, Liang F, et al. Regulation of phagocytosis in macrophages by neuraminidase 1 . J Biol Chem 285: 206215, 2010.

40. Gornik O, Wagner J, Pucic M, Knezevic A, Redzic I, Lauc G. Stability of N-glycan profiles in human plasma. Glycobiology 19: 1547-1553, 2009.

41. Darveau M, Denault AY, Blais N, Notebaert E. Bench-to-bedside review: iron metabolism in critically ill patients. Crit Care 8: 356- 
Intern Med 50: 861-869, 2011 DOI: 10.2169/internalmedicine.50.4704

362, 2004.

42. Means RT Jr. Advances in the anemia of chronic disease. Int J Hematol 70: 7-12, 1999.

43. Sears DA. Anemia of chronic disease. Med Clin North Am 76
567-579, 1992.

44. Jurado RL. Iron, infections, and anemia of inflammation. Clin Infect Dis 25: 888-895, 1997.

(C) 2011 The Japanese Society of Internal Medicine http://www.naika.or.jp/imindex.html 